\title{
No que você está pensando? apontamentos sobre opinião pública nas redes sociais digitais
}

What's on your mind? notes on public opinion on social media

¿Qué estás pensando? Notas sobre la opinión pública en las redes sociales digitales

\section{(9) Ricardo Germano Tesseroli}

- Doutorado em Comunicação pela Universidade Federal do Paraná (UFPR)

- Mestre em Comunicação pela UFPR.

- $\quad$ Especialização em Comunicação Política e Imagem pela UFPR.

- Especialização em Comunicação, Política e Atores Sociais pela Universidade Estadual de Ponta Grossa (UEPG).

- Graduação em Comunicação Social - Jornalismo pela Universidade Estadual do Centro-Oeste (Unicentro).

- Membro do Grupo de Pesquisa Comunicação Eleitoral (CEL/UFPR).

- $\quad$ E-mail: rgtesseroli@gmail.com

\section{(9) Pedro Chapaval Pimentel}

- Doutorando em Administração pela UFPR.

- Mestre em Comunicação pela UFPR.

- Especialização em Relações Internacionais e Diplomacia pelo Centro Universitário Curitiba (Unicuritiba).

- Graduação em Comunicação Social pela UFPR e em Administração pela FAE Centro Universitário.

- Membro do Grupo de Pesquisa Comunicação Eleitoral (CEL) e Grupo de Pesquisa Estratégias de Marketing, ambos da UFPR.

- E-mail: professorchapaval@gmail.com 


\section{Resumo}

Este ensaio apresenta a evolução histórica de discussões sobre a opinião pública resgatando, para isso, os principais conceitos e teorias que proporcionaram o atual estado da questão. A partir dessas considerações, propõe-se uma reflexão crítica sobre o papel da opinião pública na contemporaneidade e do seu papel em um contexto de redes sociais digitais.

\section{PALAVRAS-CHAVE: COMUNICAÇÃO • OPINIÃO PÚBLICA •ESFERA PÚBLICA・REDES SOCIAIS DIGITAIS.}

\section{Abstract}

The essay presents the historical evolution of debates on public opinion, rescuing, for that, the main concepts and theories that provided the current state of the knowledge. Based on these considerations, a critical reflection is proposed on the role of public opinion in our contemporaneity and its role within a social media context.

KEYWORDS: COMMUNICATION • PUBLIC OPINION • PUBLIC SPHERE・SOCIAL MEDIA.

\section{Resumen}

Este ensayo presenta la evolución histórica de los debates sobre la opinión pública rescatando algunos de los principales conceptos y teorías que proporcionaron el actual estado del conocimiento. Con base en estas consideraciones, se propone una reflexión crítica sobre el papel de la opinión pública en la contemporaneidad y su papel en un contexto de redes sociales digitales. 
A opinião pública não existe. Com essa afirmação, Bourdieu (1982) conclui seu ensaio para dizer que a maneira como alguns a concebem estaria equivocada. Hoje, redes sociais digitais induzem-nos a pensar e manifestar nossas opiniões; caso do Facebook e sua pergunta: "No que você está pensando?". Uma busca em dicionários e enciclopédias mostra que boa parte das definições sobre opinião pública convergem para o entendimento de que ela é o conjunto de ideias, opiniões e valores de uma sociedade em relação a um determinado assunto. Ou, então, a opinião predominante em uma sociedade.

Trabalhar a opinião pública tornou-se crítico na contemporaneidade; este é um cenário em que as mídias tradicionais e formadores de opinião convivem e utilizam uma infinidade de plataformas digitais que dão voz a inúmeros enunciadores de informação. É a partir da necessidade de discutir e refletir sobre desafios relacionados à opinião pública trazida nesta edição que desenvolvemos este ensaio.

Nosso objetivo é fazer um resgate dos principais conceitos e teorias do entendimento de opinião pública, auxiliando acadêmicos em suas pesquisas e cidadãos a avaliar a realidade de forma crítica. A partir disso, propomos uma reflexão sobre qual é 0 papel da opinião pública em um contexto de informações descentralizadas por meio das redes sociais digitais e apontamos direções para futuras pesquisas.

Este ensaio está estruturado em cinco seções. Após esta introdução, realizamos um resgate histórico, ainda que anacrônico, da evolução do conceito até chegar na atualidade. Em seguida, apresentamos as principais perspectivas teóricas intercorrentes ao fenômeno. Na quarta seção dissertamos sobre a opinião pública contemporânea e aspectos relacionados às redes sociais digitais. Concluímos o ensaio apontando desdobramentos e sugestões para futuras pesquisas.

\section{MATIZES HISTÓRICAS DO FENÔMENO}

Da antiguidade clássica, passando pela idade média até chegar à contemporaneidade, a opinião pública é conceituada de diferentes formas. Os romanos atribuíam um sentido jurídico à expressão consensus populi (consenso popular). Os Gregos entendiam ser possível encontrá-la nos debates na Ágora ateniense, onde participavam apenas homens livres e com posses. Na idade média, a voz do povo era a voz do próprio Deus (vox Populi, vox Del).

0 termo opinião pública, referenciando à participação da população em questões de interesse público, só apareceu em meados do século XVIII, quando Rousseau (2011) propôs que a soberania e as leis são decorrentes exclusivamente da vontade do povo. Entretanto, foi somente em 1922 que Walter Lippmann (2017) cravou o início da discussão sobre opinião pública nos tempos modernos.

Lippmann (2017) recorre às imagens que formamos na nossa cabeça para explicar a ideia de que a opinião seria "a média das opiniões circundantes em uma determinada sociedade, num momento determinado" (Ferreira, 2015, p.63). Quando as pessoas procuram emitir suas opiniões racionalmente, deve-se levar em conta que possuem em sua mente uma série de ideias e imagens. A metáfora é usada para demonstrar que, para formularmos um pensamento sobre determinada coisa, usualmente recorremos às imagens que temos guardadas em nossa mente. 
Essas imagens, oriundas das interações sociais e do que temos contato por meio da imprensa, são o alicerce das informações que vamos utilizar em nosso processo de construção da opinião. "Teremos que presumir que o que cada homem faz está baseado, não em conhecimento direto e determinado, mas em imagens feitas por ele mesmo ou transmitidas a ele" (Lippmann, 2017, p.37).

Essa argumentação é usada então para delimitar o que Lippmann considera opinião pública e Opinião Pública. A primeira (em minúsculo) diz respeito às imagens que formamos na nossa mente provenientes de construções culturais e de relações com outras pessoas. Já a segunda (com letras maiúsculas), é fruto da ação de grupos de interesse (entre eles a mídia) ou de pessoas que agem em nome desses grupos (formadores de opinião). A opinião reconhecida como pública seria então uma opinião tornada pública e aceita pelo público, e não uma opinião surgida no público!.

A opinião pública em Lippmann seria formada por uma série de imagens mentais, baseadas em estereótipos, que a sociedade resolve aceitar como verdadeiro. Nesse aspecto, vale abrir um parêntese e destacar o papel da publicidade dentro de todo esse contexto comunicacional, afinal, "o que é a propaganda, senão o esforço para alterar a imagem a qual os homens respondem, substituindo um padrão social por outro?" (Lippmann, 2017, p. 38). Com essa observação, o autor coloca a propaganda como uma das responsáveis por plantar as imagens em nossa cabeça e, dentro de um contexto de grupos de interesse, essas imagens fazem com que um determinado padrão de opinião seja substituído por outro.

Lippmann (2017) elabora sua conceituação partindo do pressuposto de que as pessoas são impossibilitadas de ter um conhecimento direto da realidade e que esse conhecimento seria obtido pelos meios de comunicação. Assim, as teorias que predominaram até a década de 1950 afirmavam que o cidadão comum tinha conhecimento da realidade através dos meios de comunicação, dando poder à mídia sobre a opinião pública, já que a sociedade era formada por indivíduos que se informavam, basicamente, por meios dos jornais, rádio e televisão.

De qualquer maneira, é no estudo habermasiano sobre esfera pública que temos o ponto de partida para a compreensão da teoria criada em torno deste fenômeno. 0 entendimento de Habermas (1984) sobre esfera pública tem a ver com a existência de uma arena de discussão e debate público, seja formal ou informal, voltada à burguesia letrada. A esfera pública surge então nos salões, cafés e ambientes privados, na Europa dos séculos XVII-XVIII, onde a burguesia se encontrava para discutir assuntos do cotidiano, um paradoxo entre o público e o privado que se constrói ao menos desde a Ágora ateniense. Para Habermas (1984), a esfera pública seria um local de debate onde os assuntos de interesse geral podem ser discutidos e opiniões formadas.

A esfera pública era originada e se mantinha na presença de iguais, afinal, burgueses com igualdade de status se reuniam e discutiam à margem das instituições políticas. Essa era "uma esfera pública das pessoas privadas" (Habermas, 1984, p. 144), pois pessoas privadas se reuniam em público para defender a liberdade econômica e combater a dominação do Estado.

O desenvolvimento completo de uma esfera pública, contudo, não se concretiza e essa dificuldade se dá historicamente por três motivos: (1) a institucionalização baseada na abertura do espaço de discussão para setores da sociedade que começavam a se organizar com os representantes de classes trabalhadoras, partidos políticos e sindicatos; (2) a crescente intervenção do Estado em toda sociedade e (3) a crescente influência da mídia.

Para Habermas (2003; 1984), a discussão democrática nas sociedades modernas acabou sendo influenciada pelos meios de comunicação de massa. A questão aqui é que a "mídia amplia a esfera pública, mas, uma vez ampliada midiaticamente,

1 Ao longo deste ensaio utilizamos opinião pública no minúsculo apenas para fins didáticos, sem que isso seja referência à distinção trazida por Lippmann. 
essa esfera perde o conteúdo político original para ser mais vendável ou aceitável socialmente, fazendo com que a racionalidade ceda espaço para a forma" (Cervi, 2006, p.69). Nesse sentido, os meios de comunicação de massa coletam informações, escolhem o enquadramento e o tom sobre o que divulgar, e controlam o que irá alimentar a esfera pública e influenciar todo o sistema.

Ao analisar a esfera pública, Cervi (2006) enfatiza que com o advento do rádio e da televisão, a "esfera pública se amplia e se modifica em função dos interesses privados presentes no sistema, fazendo com que, a partir de então, ao invés da mídia intermediar a opinião pública, ela passe a produzir elementos para a formação de opinião", (Cervi, 2006, p.90).

No entanto, mesmo com toda essa lógica comunicacional, não é possível delinear claramente os papéis de cada um dos atores envolvidos no processo de construção da esfera pública. Afinal, não seria possível ter clareza sobre como os meios de comunicação afetam os fluxos de comunicação da esfera pública "mesmo que conhecêssemos o peso e o modo de operar dos meios de comunicação de massa e a distribuição de papéis entre público e atores, e mesmo que pudéssemos opinar sobre quem dispõe do poder dos meios" (Habermas, 2003, p.111).

Habermas define ainda três tipos de esfera pública: a esfera pública tradicional burguesa, a sua transformação/declínio com a incorporação de entidades de representação civil, e a produção da sensação de esfera pública criada pelos meios de comunicação de massa. Em todas essas esferas, os cidadãos interpretam uma determinada situação e, em suas interações cotidianas, começam a constituir contextos comunicacionais dando forma à esfera pública.

Podemos destacar que a formação da opinião de cada indivíduo, que resultará na opinião pública, acontece idealmente em um ato de fusão de informações. De posse de um repertório e subjetividade individual, cada pessoa toma conhecimento de um fato pelos meios de comunicação ou pares, formula seus conceitos e depois discute com outros membros da sua esfera. Cada um desses membros possui opinião própria, a partir do que construiu por meio da sua subjetividade e informações dos meios de comunicação. Na junção de todos esses elementos é que se viabilizam e se formam as opiniões da esfera pública, formando constelações de discursos e, consequentemente, a opinião pública (Pimenta, 2007).

Não é possível delimitar o espaço da esfera pública apenas nos espaços privados de bares e cafés. A esfera pública ganhou novos significados, principalmente após a popularização das redes sociais digitais. Mas quais seriam esses novos significados? Essa é uma das inquietações que nos moveu a pensar este estudo, para iniciar uma inquietação de pensamento que possa ser levada a diante por outros pesquisadores.

Se transpormos esse contexto de esfera pública tradicional para as redes sociais digitais, podemos enfatizar que apesar de Habermas privilegiar os espaços concretos de um público presencial alertamos para a substituição das interações presenciais pela presença virtual dos integrantes dessa esfera. Nela, a internet rompe a distância física e temporal, e as interações passam a ser realizadas por meio virtual, formando uma esfera pública interconectada. Seria possível moderar preocupações relacionadas às mídias tradicionais, como o excessivo poder que a mídia dá aos seus proprietários e a sua tendência de concentrar poder dos proprietários e/ou encorajar uma política inerte (Côrbo, 2015)? Uma esfera pública interconectada proporciona debates reflexivos ou radicalizados (Jensen, 2003), e incita a mobilização de distintos atores (Xiong; Cho; Boatwright, 2019), ao menos em tese.

Quando discute-se a ideia de esfera pública Habermas, destaca-se o papel da imprensa. Podemos compreender que os meios de comunicação exercem um fator decisivo na formação dessa esfera pois possibilita que o fluxo de informações alcance os cidadãos. "Atualmente, os variados meios de comunicação, em especial Internet, estão incluindo em nossas preocupações certos temas que, de outro modo, não chegariam a nosso conhecimento e, muito menos, tornar-se-iam temas de nossa 
agenda" (Medeiros, 2013, p.30). Nesse caso, a internet é capaz de fornecer informações de forma rápida e as redes sociais digitais possibilitam o debate entre integrantes da esfera que não se encontram presencialmente ligados.

Habermas também deu sua contribuição para o conceito de opinião pública, pois "a opinião do público pensante não é mais simplesmente opinion, não se origina de uma mera inclination, mas é uma reflexão privada sobre os public affairs, e a discussão pública deles" (Habermas, 1984, p.116). 0 conceito de esfera pública está implícito à opinião do público, pois essa opinião não se origina somente de uma inclinação do pensamento dos integrantes dessa esfera, mas também de uma reflexão pública a partir dos assuntos públicos. A opinião pública em Habermas (1984) é formada dentro da esfera pública e é uma opinião crítica, formulada por cidadãos privados, membros da burguesia que interagem entre si, em um processo racional de argumentação. Os cidadãos nessa esfera conversam sobre um determinado tema, constroem um contexto comunicacional, chegam a um consenso e dão forma à opinião pública.

Outras correntes de pensamento que ganharam notoriedade na segunda metade do século XX mostram diferentes olhares sobre a formação da opinião pública. Muitas delas com uma visão elitista e atribuindo aos meios de comunicação de massa um papel de protagonista na formação deste conceito. A hipótese do Agendamento, por exemplo, parte da premissa de que os meios de comunicação estabelecem uma agenda de assuntos, definindo os temas sobre os quais o público será informado e consequentemente sobre o que eles vão pensar a respeito. Para McCombs e Shaw (1972), os meios de comunicação selecionam os temas sobre os quais o público deve formar uma opinião, ainda que ela não seja capaz de impor uma opinião já formada.

Já a hipótese da Espiral do Silêncio parte da premissa de que os cidadãos tendem a acompanhar opiniões majoritárias, silenciando as opiniões pessoais, para fugir de um possível isolamento social. Esse fenômeno gera uma espiral que favorece a discussão do assunto majoritário em detrimento de opiniões diferentes ou contrárias. Segundo Noelle-Neuman (1974), esse efeito é produzido por aqueles que se sentem integrantes da maioria e que expressam suas opiniões, enquanto os setores minoritários tendem à autocensura.

Ambos os exemplos alertam para correntes de pensamento que atribuíam aos meios de comunicação e a comportamentos psicossociais, estimulados pelos meios de comunicação, relativo poder na formulação da opinião pública, no comportamento de indivíduos e das massas. Para essas correntes, "a opinião pública é muito parecida com a ideia de consenso básico existente em uma sociedade, sem significar que se trata de uma espécie de pacto social racional ou conscientemente acordado" (Cervi, 2006, p.115). A opinião pública pode ter ou não um caráter político, é bem mais do que a soma das opiniões individuais, e não pode ser confundida com vontade popular.

Nesse sentido, Charaudeau (2016) destaca que "não existe uma opinião pública, mas várias opiniões públicas" (p.44). A opinião pública é heterogênea, composta de vários fenômenos e que transparece em uma miríade de opiniões. Para existir como tal, a opinião pública precisa de um motivo, de acontecimentos que sejam postos diante da audiência para que ela tome conhecimento e faça emergir dessa audiência reações individuais. Assim, para que a opinião pública se manifeste, se faz necessário que algo aconteça: um fato, uma ocorrência, algo palpável que provoque a reação de um grupo de indivíduos.

Ao problematizar o paradoxo público-privado, Figueiredo e Cervellini (1995) destacaram a importância de a opinião pública corresponder às opiniões de grupos de pessoas com características em comum, independentemente de seu pertencimento a elites ou massas, maiorias ou minorias. A opinião de todos deveria ser considerada "igualmente como uma das formas de manifestação da opinião pública (Figueiredo; Cervellini, 1995, p.177).

Sob esse prisma, podemos constatar uma diferenciação da evolução do conceito de opinião pública - desde Habermas e sua esfera pública até Charaudeau, passando por Lippmann, McCombs e Shaw e Noelle-Neuman. Apontamos, contudo, 
que 0 aprofundamento dos estudos sobre opinião pública tornou o conceito, com o passar dos anos, cada vez mais amplo e complexo. Contemporaneamente, abrangência e extensão das fontes de emissão de opinião se multiplicaram de modo exponencial e, em decorrência das novas plataformas e dispositivos de comunicação, todo indivíduo pode ser um formador de opinião em potencial (Farias, 2019).

Como resultado, Farias (2019) aponta criticamente que a perspectiva de que a opinião pública seria formada pelo exercício do contraditório vem se apagando. Já não há debates, mas endosso às cegas. No ambiente de redes sociais digitais, aumenta-se o risco da inexistência de critérios avaliativos para o que é verdade. A opinião pública é, muitas vezes, trabalhada a partir do verossímil e com base em argumentos falaciosos.

Antes, debates eram vencidos pela palavra antifônica, impedindo que situações conflitantes fossem resolvidas "sem aniquilar fisicamente o adversário" (Fiorin, 2015, p.26). Hoje, enxergamos por meio das redes sociais digitais 0 aumento da ira (Farias, 2019), as diferenças passaram a ser resolvidas de forma ofensiva, pois "abandona-se completamente o objeto e dirige-se o próprio ataque à pessoa do adversário: tornamo-nos, portanto, insolentes, maliciosos, insultantes, indelicados" (Schopenhauer, 2009, p.53).

Assim, de uma esfera pública burguesa letrada, o conceito passou a abranger indivíduos heterogêneos, além de ser formado, também, por minorias e novas plataformas e tecnologias que complexificaram a sua instrumentalização e compreensão. Diante desse contexto, detalhamos a seguir elementos que compõem a complexidade das análises a partir do e sobre o fenômeno.

\section{DA COMPLEXIDADE À INSTRUMENTALIDADE}

Ao compreender aspectos desse arcabouço teórico composto por diferentes dimensões, é necessário lembrar que o fenômeno em questão está no mundo e que é preciso olhar para ele e apropriar-se dele como um objeto (Tsoukas; Chia, 2011). Logo, para instrumentalizar o fenômeno da opinião pública como um objeto de estudo, exploramos os seguintes elementos: direção, intensidade, coerência ou consistência e latência.

0 conceito de direção está alicerçado no posicionamento da opinião pública a respeito de determinado tema que emergiu da sociedade, informando "se determinado grupo está a favor ou contra alguma coisa". (Figueiredo; Cervellini, 1995, p.180). Logo, "tanto individualmente quanto do ponto de vista coletivo, são produzidas disposições gerais no sentido de adesão ou rejeição a uma ideia, com respostas positivas ou negativas" (Cervi, 2006, p.118). Para além do posicionamento contra ou a favor, temos o conceito de esquerda e direita, tratando correntes ideologias ou ações da elite política. Esse fenômeno recente traz à direção uma dimensão praticamente lúdica na explicação de sua conceituação, criando inclusive diferentes níveis de um pêndulo que varia da extrema-direita à extrema-esquerda, por exemplo.

A intensidade pode ser entendida como o "grau de adesão a cada opinião, dando uma medida de força da manifestação. Pode-se imaginar facilmente que os efeitos de uma situação em que a opinião pública é muito intensa são bem diferentes daqueles em que a força da adesão é menor" (Figueiredo; Cervellini, 1995, p.180). A intensidade ajuda a explicar por que algumas pessoas se sentem mais aptas a formular e expressar uma opinião sobre temas em detrimento a outros; ela está intimamente ligada à força da opinião pública. Podem existir opiniões com considerável força, mas que duram um curto espaço de tempo e opiniões que não demonstram tanta força, mas se mantém em evidência por um maior período. 0 papel das redes sociais digitais e da autonomia dos indivíduos auxiliam na disseminação de mensagens em uma era de pós-verdade e fake news, em que pseudoteorias conspiratórias reverberam com intensidade, encontrando espaço nos meios de comunicação tradicionais. 
A consistência e a coerência da opinião pública podem ser percebidas quando está em jogo um assunto de impacto social ou um tema controverso. Quando é difícil para um número considerável de indivíduos entenderem as questões discutidas, a probabilidade dessa opinião não ter muita consistência ou coerência é grande. Por exemplo, entrevistados podem apresentar argumentações conflituosas ao afirmar que o governo pode definir políticas migratórias banindo aqueles que não contribuiriam com a economia, e simultaneamente serem favoráveis ao acolhimento de refugiados por motivos políticos ou religiosos. Argumentações contraditórias e incoerências lógicas podem surgir na análise de determinado tema pois a consistência "tem relação com a organização, pois quanto maior o grau de consistência interna de uma opinião, melhor será a organização de um cluster de opiniões" (Cervi, 2006, p.120).

A latência diz respeito ao estado de hibernação da opinião pública em oposição à ativação, isto é, ao potencial existente para uma manifestação que ainda não veio à público e que depende de estímulos relacionados aos valores, crenças e atitudes básicas de um indivíduo (Figueiredo; Cervellini, 1995). A latência da opinião pública tem a ver, então, com uma opinião com potencial para se tornar intensa, mas que ainda não foi explicitada e dessa forma não foi ativada. Essa ativação depende de um estímulo para trazer a discussão à tona e assim despertar o assunto. Para alguns, políticas de acolhimento à refugiados podem ser um tema irrelevante, mas tem latência para se tornar crítico quando algum líder de opinião diz que refugiados roubam empregos da população local, por exemplo.

Não podemos ignorar a atualização das notícias paralelamente à repetição daquelas mais relevantes (mas de acordo com a avaliação de quem?). Isso nos alerta para o envolvimento da mídia na formação da opinião pública e na sua instrumentalização. Para Olicshevis (2006), a mídia tem a capacidade de formular questões públicas e, ao fazer isso, alimenta a audiência e faz com que o público passe a formar uma opinião pública a respeito dos assuntos que trouxe à tona.

Uma das grandes questões contemporâneas sobre a opinião pública reside na velocidade com que as informações circulam, na variedade de fontes emissoras e na abrangência e heterogeneidade dos tópicos tratados por grupos de pressão e líderes de opinião oriundos desse universo digital. Ao que diz respeito às mudanças de opinião que ocorreriam individualmente, geradas por autorreflexão e/ou socialmente, definidas por rupturas ideológicas (Cervi, 2006), as redes sociais digitais proporcionaram um ponto de inflexão.

Notícias ou os assuntos dignos de debate acabam dispostos de forma a persuadir os indivíduos a aceitarem outros pontos de vista, em oposição ao convencimento racional. Parece-nos que a capacidade de autorreflexão decorrente da racionalidade e do amadurecimento dos indivíduos enquanto cidadãos vem sendo colocada em cheque a partir do momento em que redes sociais digitais passaram a conviver com os tradicionais meios de comunicação, descontruindo fatos e implicando em "novas verdades".

\section{A OPINIÃO PÚBLICA NO CONTEXTO DE REDES SOCIAIS DIGITAIS}

Nas últimas três décadas, os estudos sobre opinião pública passaram a mirar um novo elemento comunicacional. 0 foco da discussão sobre opinião pública recaiu sobre a internet e as redes sociais (Facebook, Twitter, TikTok etc.) digitais trazendo ênfase à circulação das informações em redes e seu papel na formação da opinião pública (Kaiser etal., 2017). Vale destacar que as informações circulam de modo diferente nas mídias digitais se comparada à circulação de informações na esfera pública burguesa ou nos tradicionais meios de comunicação de massa. Afinal, a reconfiguração do campo midiático resultante das tecnologias da informação e da comunicação trouxe mudanças na forma como se estabelecem relações sociais, como práticas comunicativas se desenvolvem e nas possibilidades interativas entre inúmeros atores sociais (Terra; De Sousa, 2019). 
Na internet, temos duas questões fundamentais que interferem na circulação de informação. A primeira diz respeito à miríade de atores que, a partir de motivações baseadas em suas percepções individuais, filtram e replicam as informações, tornando-as visíveis para o restante da rede (Recuero, 2010). Esses atores teriam o poder de fazer uma curadoria de informações ao levar algumas informações a ganharem visibilidade e outras não, potencializando um discurso e silenciando outro. "Essas ações, de modo coletivo, acabam influenciando as informações que circulam e criando processos de difusão" (Soares; Recuero, 2017, p.20-21). Neste sentido, a construção da opinião pública depende da ação de difusão de informações que são tomadas pelos atores nas redes sociais digitais, e a participação de formadores de opinião em dois passos (Bennet; Manheim, 2006) torna-se ainda mais relevante; atores como Felipe Neto ou Olavo de Carvalho passam a potencializar mensagens com e para diferentes públicos.

O papel desempenhado pelos algoritmos interfere ao selecionar as informações consideradas importantes pelos e para os usuários da internet. "Os algoritmos projetados para calcular o que 'está em alta', o que é 'tendência' ou o que é 'mais discutido' nos oferecem uma camada superficial das conversas aparentemente sem fim que estão disponíveis" (Gillespie, 2018, p.96). Esses colaborariam com a hipótese da Espiral do Silêncio, dando mais destaque aos trending topics ou a visões preponderantes, e silenciando opiniões com menor adesão.

A opinião pública em tempos digitais estaria condicionada aos algoritmos, que podem estar "legitimando visões de verdade e razão, e a compreensão de que ao se ter determinadas visões de mundo reforçadas o tempo todo, não exista mais o espaço de criação de uma opinião de fato pública" (Fantini; Jandoso, 2018, p.98). Ainda mais problemática é a produção de conteúdo noticioso falso, ou fake news, em escala industrial para que sejam alcançados objetivos escusos. A isso, Farias $(2019$, p.106) acrescenta à ideia de pós-verdade, isto é, quando se coloca "sentimentos em lugar da razão, fazendo com que grupos predispostos ou sensibilizados a dado comportamento aceitem mais facilmente distorções em favor de suas crenças".

De forma silenciosa e constante, o uso de algoritmos no contexto mencionado poderia auxiliar na criação de convenções e consensos destinados a cada público, a partir somente da visão de interesse de cada usuário, criando uma bolha ideológica que inviabilizaria a formação de uma opinião pública de fato. Como resultado, destacam Terra e De Sousa (2019), a formação dessas bolhas não permitem que indivíduos vejam para fora do seu próprio círculo, tornando-se aprisionados apenas àquilo que conhecem e concordam. Não há diversidade, diálogo, tampouco debates.

Agravam-se desafios à formação de esferas e opiniões públicas na internet, caso de fossos digitais, incivilidade, anonimato, fragmentação da deliberação, exposição seletiva dos indivíduos e homogeneização das discussões (Kaiser etal., 2017). A busca por curtidas, seguidores, e mais financiamento faz com que sejam adotadas uma perspectiva e um modus operandi totalmente distintos daqueles que imaginavam os mais otimistas (Medeiros, 2013).

Meios de comunicação tradicionais passam a se posicionar de maneira mais incisiva, alterando sua linha editorial e quebrando padrões de décadas - caso da Gazeta do Povo, no Paraná. Figuras públicas que não teriam qualquer impacto num passado recente, como Olavo de Carvalho, passam a definir e delimitar indicações políticas e políticas públicas no governo Jair Bolsonaro. O Facebook de Mark Zuckerberg compartilha e vende dados privados dos seus usuários para fins políticos. 0 YouTube restringe indiscriminadamente vídeos que não estão de acordo com suas políticas, mas que não ferem normativas sobre liberdade de expressão, caso da Prager University nos Estados Unidos.

Contudo, nessa nova dinâmica, também há oportunidades em termos de comunicação organizacional e relações públicas, responsáveis por estabelecer e manter relacionamentos mutuamente benéficos entre organizações e seus públicos (Grunig, 2003; Kunsch, 2018; Terra; De Sousa, 2019). Uma perspectiva de cocriação de valor entre diferentes organizações e públicos emerge com cada vez mais força (Vargo; Lusch, 2017). Isto é, atribui-se ao consumidor um papel ativo na geração e utilização 
do valor decorrente das trocas e experiências com organizações de modo que as relações sejam, idealmente, de ganha-ganha entre os públicos envolvidos nesses relacionamentos.

Organizações passam a mobilizar meios de relacionamento on-line e off-line para o bem comum, caso do Movimento Nós, que envolveu oito companhias de alimentos e bebidas e três grandes agências de publicidade para apoiar os negócios de pequenos varejos no contexto de isolamento social decorrente da pandemia de COVID-19 (MOVIMENTO..., 2020). Não apenas isso, mas consumidores ganham voz e suas demandas passam a ser ouvidas e, muitas vezes, atendidas por empresas de SaaS (Software as a Service) como Netflix e Spotify, e redes de fast-food como Burguer King e McDonald's.

Ainda, a utilização de novas plataformas e linguagens indicam o surgimento de novos campos de atuação, focados no "estreitamento das relações com os mais diversos públicos de interesses por meio das interações nas redes de relacionamento online, uma vez que não se pode mais dissociar as organizações do digital." (Terra; De Sousa, 2019, p. 9). Com a internet, é possível segmentar públicos não apenas em termos de mercados-alvo, mas customizar produtos e serviços para indivíduos, em segmentos-de-um, conforme indicado por Thoeni, Marshall e Campbell (2016).

Diante dessa breve reflexão, levantamos as seguintes perguntas que podem direcionar futuras pesquisas: como diferentes organizações têm respondido aos desafios e oportunidades trazidas pelas redes sociais digitais? Quais os limites de atuação de organizações públicas e privadas ao lidar com a opinião pública? Qual responsabilidade deve ser atribuída a pessoas físicas e jurídicas nesse movimento que envolve tantos atores quanto opiniões? Quais são o papel e os limites para a atuação jornalística ou não jornalística? Quais os impactos dessas transformações na democracia como conhecemos hoje? Destacamos, assim, que em um momento cujas mudanças de paradigmas políticos são ao menos em parte resultantes das redes sociais digitais, faz-se ainda mais necessário inflexionar sobre essas questões.

\section{CONSIDERAÇÕES FINAIS}

Ao passar por diversas lentes dos estudos sobre opinião pública, percebemos o quanto eles são complexos. Há uma variação do entendimento sobre opinião pública desde a antiguidade clássica até a contemporaneidade, quando diversas plataformas dominam a distribuição das informações. Assim, a percepção e definição da opinião pública sofreram alterações resultantes de mudanças e desafios tecnológicos, sociais e onto-epistemológicos.

A opinião pública é fruto de posicionamentos de indivíduos sobre temas específicos. Dessa forma, possui como tendência a heterogeneidade de opiniões acima de tudo, por mais que seja influenciada pela burguesia, pelos meios de comunicação, por pesquisas, formadores de opinião ou pelas redes. Para existir opinião pública, precisa haver deliberação, discussão e os indivíduos devem ser expostos não somente ao posicionamento dominante, mas terem acesso ao contraditório. Do contrário, não há a formação da opinião pública propriamente dita.

A opinião pública existe tanto na esfera pública presencial quanto virtual, e essas opiniões podem se fundir, misturar ou se retroalimentar. A interação mediada pela internet requer que passemos a olhar com atenção maior esses novos fluxos de comunicação, e é isto que pretendemos incentivar com este ensaio: o pensamento sobre a opinião pública nos tempos atuais, como se forma, de que se alimenta, por quem é influenciada ou quem influencia - pensamentos pertinentes para um campo de estudo que ainda carece de amadurecimento intelectual dado a velocidade com que as mudanças ocorrem tanto na esfera pública quanto na opinião pública. 


\section{REFERENNCIAS}

BENNETT, W. Lance; MANHEIM, Jarol B. The one-step flow of communication. The ANNALS of the American Academy of Political and Social Science,Thousand Oaks, v.608, n.1, p.213-232, 2006. doi: 10.1177/0002716206292266. Acesso em: 26 out. 2020.

BOURDIEU, Pierre. A opinião pública não existe. In: THIOLLENT, Michel. Crítica metodológica e investigação social e enquete operária. São Paulo: Polis, 1982.

MOVIMENTO nós. Clube de Criação, São Paulo, 03 ago. 2020. Disponível em: https://www.clubedecriacao.com.br/ultimas/ movimento-nos/. Acesso em: 26 out. 2020.

CERVI, Emerson Urizzi. Opinião pública e política no Brasil: o que o brasileiro pensa sobre política e porque isso interessa à democracia. 2006. Tese (Doutorado em Ciência Política) - Instituto Universitário de Pesquisas do Rio de Janeiro, Rio de Janeiro, 2006. Disponível em: http://doxa.iesp.uerj.br/wp-content/uploads/2016/02/URIZZI_2006.pdf. Acesso em: 26 out. 2020.

CHARAUDEAU, Patrick. A conquista da opinião pública: como o discurso manipula as escolhas políticas. São Paulo: Contexto, 2016.

CÔRBO, Dayo de Araújo Silva; GONÇALVES, Márcio. Redes sociais digitais na esfera pública política: exercícios de cidadania. Revista Mídia e Cotidiano, Niterói, v.6, n.6, p.152-168, 2015.

FANTINI, João Angelo; JANDOSO, Bruna. Algoritmos do Facebook: impactos na formação de opinião e grupos em processos políticos. Leitura Flutuante, São Paulo, v.10, n.1, p.87-102, 2018.

FARIAS, Luiz-Alberto de. Opiniões voláteis: opinião pública e construção de sentido. São Bernardo do Campo: Editora Metodista, 2019.

FERREIRA, Fernanda Vasques. Raízes históricas do conceito de opinião pública em comunicação. Em Debate, Belo Horizonte, v.7, n.1, p.50-68, 2015.

FIGUEIREDO, Rubens; CERVELLINI, Sílvia Penteado. Contribuições para o conceito de opinião pública. Opinião Pública, Campinas, v.3, n.3, p.171-185, 1995.

FIORIN, José Luiz. Argumentação. São Paulo: Contexto, 2015

GILLESPIE, Tarleton. A relevância dos algoritmos. Parágrafo, São Paulo, v.6, n.1, p.95-121, 2018.

GRUNIG, James E. A função das relações públicas na administração e sua contribuição para a efetividade organizacional e societal. Comunicação e Sociedade, São Bernardo do Campo, v.24, n.39, p.67-92, 2003. doi: 10.15603/2175-7755/cs.v24n39p67-92. Acesso em: 26 out. 2020.

HABERMAS, Jürgen. Direito e democracia: entre facticidade e validade. Rio de Janeiro: Tempo Brasileiro, 2003.

HABERMAS, Jürgen. Mudança estrutural da esfera pública. Rio de Janeiro: Tempo Brasileiro, 1984. 
JENSEN, Jakob Linaa. Public spheres on the internet: anarchic or government-sponsored - a comparison. Scandinavan Political Studies, Hoboken, v.26, n.4, 2003.

KAISER, Jonas; FÄHNRICH, Birte; RHOMBERG, Markus; FILZMAIER, Peter. What happened to the public sphere? The networked public sphere and public opinion formation. In: CARAYANNIS, Elias G.; CAMPBELL, David F. J.; EFTHYMIOPOLOS, Marios Panagiotis (eds.). Handbook of cyber-development, cyber-democracy, and cyber-defense. New York: Springer, 2017. doi: 10.1007/978-3-319-06091-0_31-1. Acesso em: 26 out. 2020.

KUNSCH, Margarida M. Krohling. A comunicação estratégica nas organizações contemporâneas. Media e Jornalismo, Lisboa, v.18, n.33, p.13-24, 2018.

LIPPMANN, Walter. Opinião pública. Petrópolis: Vozes, 2017.

MCCOMBS, Maxwell; SHAW, Donald L. The agenda-setting function of mass media. Public Opinion Quartely, Washington, DC, v.36, n.2, p.176-187, 1972.

MEDEIROS, Jackson da Silva. Considerações sobre a esfera pública: redes sociais na internet e participação política. TransInformação, Campinas, v.25, n.1, p.27-33, 2013.

NOELLE-NEUMANN, Elisabeth. The spiral of silence: a theory of public opinion. Journal of Communication, Hoboken, v.24, n.2, p.43-51, 1974.

OLICSHEVIS, Giovana. Mídia e opinião pública. Revista Vernáculo, Curitiba, n.17-18, p.91-99, 2006.

PIMENTA, Lidiane Malagone. A formação da opinião pública e as inter-relações com a mídia e o sistema político. In: CONGRESSO DA ASSOCIAÇÃO BRASILEIRA DE PESQUISADORES EM COMUNICAÇÃO E POLÍTICA, 2., 2007, Belo Horizonte. Anais [...] Belo Horizonte: Universidade Federal de Minas Gerais,2007.

RECUERO, Raquel. Redes sociais na internet. Porto Alegre: Sulina, 2010.

ROUSSEAU, Jean-Jacques. Do contrato social ou princípios do direito político. São Paulo: Companhia das Letras, 2011.

SCHOPENHAUER, Arthur. A arte de ter razão: exposta em 38 estratagemas. 3. ed. São Paulo: Martins Fontes, 2009.

SOARES, Felipe Bonow; RECUERO, Raquel. Opinião pública no Twitter: análise da indicação de Alexandre de Moraes ao STF. Logeion: Filosofia da Informação, Rio de Janeiro, v.3, n.2, p.18-37, 2017.

TERRA, Carolina Frazon; DE SOUSA, Gisela Maria Santos Ferreira. Opinião pública em tempos de mídias sociais: midiatização, comunicação desintermediada m memes. In:CONGRESSO BRASILEIRO CIENTÍFICO DE COMUNICAÇÃO ORGANIZACIONAL E DE RELAÇÕES PÚBLICAS, 13., 2019, São Paulo. Anais [...]. São Paulo: Faculdade Cásper Líbero, 2019.

THOENI, Andrew T.; MARSHALL, Greg W.; CAMPBELL, Stacy M. A resource-advantage theory typology of strategic segmentation. European Journal of Marketing, Bingley, v.50, n.12, p.2192-2215, 2016. doi:10.1108/EJM-08-2015-0585. Acesso em: 26 out. 2020. 
VARGO, Stephen L.; LUSCH, Robert F. Service-dominant logic 2025. International Journal of Research in Marketing, Amsterdam, v.34, n.1, p. 46-67, 2017. doi: 10.1016/j.ijresmar.2016.11.001. Acesso em: 26 out. 2020.

XIONG Ying; CHO Moon-hee; BOATWRIGHT, Brandon. Hashtag activism and message frames among social movement organizations: Semantic network analysis and thematic analysis of Twitter during the \#MeToo movement. Public Relations Review, Amsterdam, v.45, n.1, p.10-23, 2019. doi: 10.1016/j.pubrev.2018.10.014. Acesso em: ago. 2020.

Artigo recebido em 27/05/2020 e aprovado em 08/10/2020. 